\title{
Enhanced Epithelialization by Adipose-derived Stem Cells
}

\author{
PManuel Meruane ${ }^{1,2^{*}}$, Susana Benitez ${ }^{3}$, Mariana Rojas ${ }^{1}$, Alfredo Sagredo ${ }^{4}$, \\ Katherine Marcelain ${ }^{5}$ and Bruno Villalobos ${ }^{6}$ \\ ${ }^{1}$ Program of Anatomy and Developmental Biology, Faculty of Medicine, University of Chile, Santiago, \\ Chile \\ ${ }^{2}$ Department of Plastic Surgery, Clínica Tabancura, Santiago, Chile \\ ${ }^{3}$ Department of Plastic Surgery, Clínica Las Condes, Santiago, Chile \\ ${ }^{4}$ Program of Pathophysiology, Faculty of Medicine, University of Chile, Santiago, Chile \\ ${ }^{5}$ Program of Human Genetics, Faculty of Medicine, University of Chile, Santiago, Chile \\ ${ }^{6}$ Hospital de Carabineros, Santiago, Chile
}

Received: June 23, 2017; Accepted: August 16, 2017; Published: September 15, 2017

*Corresponding author: Manuel Meruane, MD, MSc, Program of Anatomy and Developmental Biology, Faculty of Medicine, University of Chile Av. Independencia 1027, Santiago, Chile, Tel: (+56 2)29786848; E-mail: mmeruane@vtr.net

\begin{abstract}
Skin regeneration has improved significantly with the advent of bioengineered tissue. Previous studies showed that the use of dermal substitutes combined with autologous Adipose-derived Stem Cells (ASCs) improve angiogenesis and collagen synthesis; however epithelialization is an outstanding issue to be resolved. In the present study, we evaluated the epithelial progression and differentiation in an extended period of time. We obtained ASCs from the inguinal fat pad of 4 Sprague Dawley rats. The non-expanded cells were cultivated in a commercially available dermal substitute for 48 hours and marked with a green fluorescent protein (GFP) lentiviral vector. The scaffold plus the stem cells and a cell-free scaffold (control) were implanted in the same rats. After 4 weeks, the epithelial surface was assessed by planimetry and histology. The wound closure by epithelialization was significantly higher in the ASC side $(93.47 \% \pm 5.98 \%$ vs. $79.88 \% \pm$ $6.28 \%, \mathrm{P}=0.0028)$, and also linear epithelial advancement quantified by microscopy ( $6408 \pm 275 \mu \mathrm{m}$ vs. $5375 \pm 250 \mu \mathrm{m}, \mathrm{P}<0.001)$. GFP positive cells were identified as part of the regenerated dermis but not the epidermis. The autologous ASCs seeded on a dermal substitute significantly increased epithelial formation, most likely by an induction mechanism rather than affecting differentiation.
\end{abstract}

Keywords: Epidermal epithelium; Stem cell; Adipose tissue Artificial skin;

\section{Abbreviations}

AAPE: Advanced Adipose-Derived Stem Cell Protein Extract

ASC: Adipose-derived stem cells

bFGF: Basic fibroblast growth factor

BMSC: Bone marrow-derived stem cells

BSA: Bovine Serum Albumin

EGF: Epidermal growth factor
EGFR: Epidermal growth factor receptor

FDA: Food and Drug Administration

FGF: Fibroblast growth factor

GFP: Green fluorescent protein

G-CSF: Granulocyte colony stimulating factor

GM-CSF: Granulocyte-macrophage colony-stimulating factor

HEK: Human epidermal keratinocytes

HGF: Hepatocyte growth factor

IGF: Insulin-like growth factor

IL: Interleukin

M-CSF: Macrophage colony-stimulating factor

MSCs: Mesenchymal stem cells

MTT: 3-(4, 5-dimethylthiazolyl-2)-2,5-diphenyltetrazolium bromide

PBS: phosphate-buffered saline

PDGF: Platelet-derived growth factor

ShRNA: Small hairpin RNA

SVF: Stromal vascular fraction

TGF- $\beta$ : Transforming growth factor-beta

VEGF: Vascular endothelial growth factor

\section{Introduction}

Skin regeneration after full-thickness tissue injury is a challenge for the surgeon. The most commonly used option is a 
split thickness skin graft. Although the general clinical outcome is good, this technique has several limitations, such as hard scars, retractability, and very limited mobility, along with glandular and hair loss [1].

To avoid these difficulties, tissue bioengineering is progressing steadily to develop dermal substitutes to obtain better aesthetic and functional results with the shortest regeneration time as possible [2].

Since 1981, the literature has shown the successful use of Intregra (Integra LifeSciences Corp., Plainsboro, N.J.) in humans with major burns and has been approved for use by the FDA since 1996 [3]. Actually, its range of application has extended to other clinical situations, such as the resection of giant nevus, coverage of scalp resection, and coverage of exposed tendons [4,5]. Integra consists of a matrix of bovine type I collagen and shark cartilage glycosaminoglycans that forms a porous structure shipped with a silicone film cover. When used, the matrix is colonized progressively by local cells and new vessels, and the native collagen replaces bovine collagen.

Typically between 15 and 20 days, removing the film of silicone and performing split-thickness skin grafting are necessary.

The benefits in the use of dermal substitutes conflict with the long period of vascularization and the need for a second procedure to incorporate the epidermal cells. To solve these problems and to optimize the regeneration, the stem cells have been incorporated into the matrix, mainly from the Bone Marrow (BMSCs) and adipose tissue [6-9]. The procurement of BMSCs is a painful procedure and usually leads to low yield and may lead to donor site morbidity. On the other hand, stem cells derived from adipose tissue are easy to obtain and provide a much higher yield [10].

Adipose-derived Stem Cells (ASCs) share basic characteristics similar to those obtained from bone marrow [11-14] and their ability to differentiate into multiple lineages and enhance angiogenesis has been reported in preclinical studies [15]. It is suggested that these cells exist in adult tissues for repairing or replacing [16]. However, in excessive tissue damage by trauma or burns, local availability could be affected.

We previously reported an experimental study carried out on rats, where ASCs were seeded on a dermal substitute with a brief technique. After 21 days of tissue regeneration, a significant increase of angiogenesis by $60 \%$ and collagen synthesis by $55 \%$ was found versus the control, but the increase of spontaneous epithelialization was not significant [17]. Previous studies showed epidermal differentiation of ASCs in the fourth week of regeneration in vivo but with a delay relative to the fibrovascular differentiation [6,7].

For this reason, a working hypothesis was proposed to evaluate the behavior of epithelialization in a regeneration period of 4 weeks.

The objectives were the epithelium quantification over the dermal substitute and the determination of the final destination of ASCs in relation to this neo-epithelium.

\section{Material and Methods}

\section{Study Design}

The study was carried out in four rats. In the first step, the ASCs were isolated from the inguinal fat pad and then seeded on scaffold of Integra ${ }^{\circledR}$ for $48 \mathrm{hrs}$, being marked with a lentiviralGFP vector. In the second step, the scaffold with labeled ASCs was implanted in the same group of rats (autologous implantation) versus a control implant without cells. Four weeks later, the cicatrization behavior was evaluated by planimetry and histology to quantify the epithelialized surface and the destination of the labeled ASCs.

\section{Animals and Surgery}

Four male Sprague Dawley rats with an average weight of $280 \mathrm{~g}$ were used. All of the procedures were performed with the approval of the Bioethics Committee for animal research at the Faculty of Medicine, University of Chile.

Prior to surgical procedures, the animals were anesthetized using ketamine $(80 \mathrm{mg} / \mathrm{kg}$ ) and xylazine $(8 \mathrm{mg} /$ $\mathrm{kg}$ ) intraperitoneally. The skin surface was washed with $2 \%$ chlorhexidine.

A $3 \mathrm{~cm}$ incision in the inguinal area was made to obtain the adipose tissue. Through subcutaneous dissection with Metzenbaum scissors, a sample of $1.4 \mathrm{~g}$ fat on average was taken. Hemostasis was performed, and the incision was sutured with nylon.

During the second surgical time, the resection of two opposed segments from the dorsal skin of $3.8 \mathrm{~cm}^{2}$ was made, where the scaffold plus ASCs and the control were placed, suturing the implant with separate stitches (Figure 1).
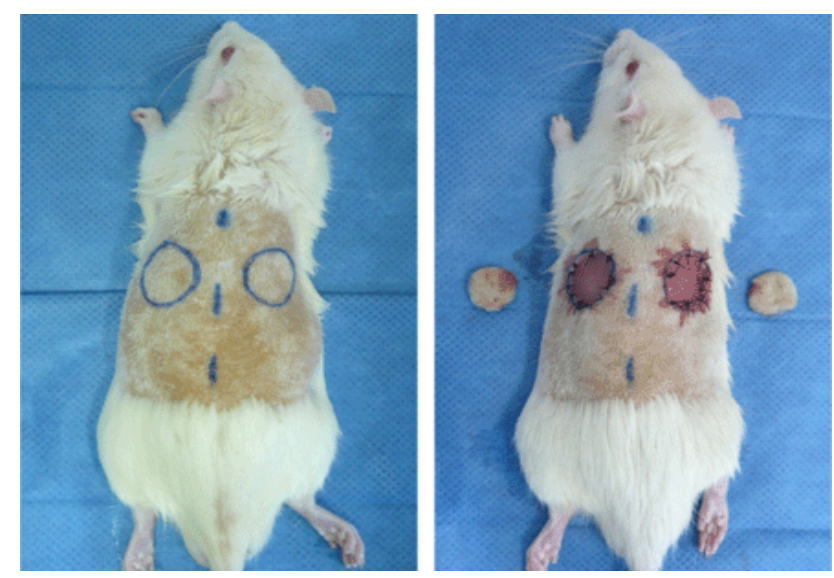

Figure 1: Replacement of dorsum skin by Integra ${ }^{\circledR}$ scaffolds. The left corresponds to the ASCs side.

The animals were kept for 4 weeks in separate cages in a sterile work environment with conditioned air, and with ad libitum feeding. The silicone sheet that protects the implant was removed at day 7 , to allow wound contraction and epithelialization. 
At the end of the study period, the rats were euthanized with an intraperitoneal overdose of sodium thiopental.

\section{Cell Isolation}

The adipose tissue sample obtained from the rat inguinal fat pad was fragmented and washed with phosphate-buffered saline (PBS). Then, enzymatic digestion with $0.01 \%$ collagenase type II was made (C6885; Sigma-Aldrich, St. Louis, Mo.) for 45 minutes at $37^{\circ} \mathrm{C}$. After digestion, the suspension was neutralized with an equal volume of culture medium (Dulbecco's Modified Eagle Medium and $10 \%$ fetal bovine serum and $1 \%$ antibiotics), passed through a $100 \mu \mathrm{m}$ sterile filter, and then centrifuged at $1200 \mathrm{G}$ for 10 minutes, resulting in a pellet with a high number of ACSs, referred to as Stromal Vascular Fraction (SVF) [18]. Generally, SVF contain $30-40 \%$ of ASCs along with endothelial, smooth muscle, and different blood cells $[19,20]$.

\section{Cell seeding on the dermal scaffold}

$3.8 \mathrm{~cm}^{2}$ circular segments of Integra ${ }^{\circledR}$ were placed in a 12 wells plate for culture with the silicone sheet side facing down. The wells were covered with $2 \mathrm{ml}$ of culture medium with an average concentration of $1 \times 10^{6}$ cells $/ \mathrm{ml}$.

In the second row of wells, the Integra scaffolds were similarly positioned to be used as controls, adding culture medium without ASCs.

The culture plate was left in an incubator at $37^{\circ} \mathrm{C}$ and $5 \% \mathrm{CO} 2$ for 48 hours; at the end of this period, only adherent cells remained in the scaffold, and the non-adherent cells were removed.

We previously determined the percentage of cell adhesion and viability of this technique by fluorescence of the CellTrace calcein on confocal microscopy and by MTT assay, viability of cells that adhered (Adherent, Adh) and did not adhere (Non-adherent, NA) to the implant, which was expressed as a percentage of the total number of cells in the culture. At $24 \mathrm{hrs}$, the viability of Adh cells was $70 \pm 22 \%$ and after $48 \mathrm{hrs}$, the viability was $87 \% \pm 21 \%$ [17].

\section{Cellular infection with a lentivirus, for expression of a fluorescent protein and cellular tracking}

After $24 \mathrm{hrs}$ of culture, the obtained cells from a rat were transduced with a commercial lentiviral vector System (Biosciences, pGreenPuro ShRNA scramble) using a multiplicity of infection of 1 . The vector-containing medium was replaced prior to grafting.

\section{Planimetric analysis to assess the percentage of cicatrization}

At day 28 of the study, the rats were euthanized. The skin on the back was resected, extended over a flat surface and photographed with a ruler to quantify the surfaces using software Axiovision 4.8 (Carl Zeiss MicroImaging GmbH, Germany).

The wound closure percentage by contraction from the edges was quantified and the area inside the edges of the implant was measured, expressing the result as described below: [(grafted area on day 0 - day 28 area)/(grafted area day 0) x 100].
Similarly, the epithelialization area was expressed as the difference between the end surface of the graft and the surface of the residual scab in the center of the implant (Figure 2A).

\section{Histological study to evaluate epithelial advancement}

After obtaining the tissue specimens, an incision was made just in the center of the lesion. Specimens were left for 48 hours in $10 \%$ formalin for tissue fixation and then embedded in paraffin. Then, serial sections of 5 microns thickness were made.

To quantify the migration of keratinocytes from the edges of the graft, the anti-cytokeratin antibody $34 \beta E 12$ high molecular weight is used (M0630; 34ßE12, 1:100, Dako Corporation, CA, USA). Epithelial advance quantification on the grafted area was made using Axio Vision software 4.8 (Figure 2B).
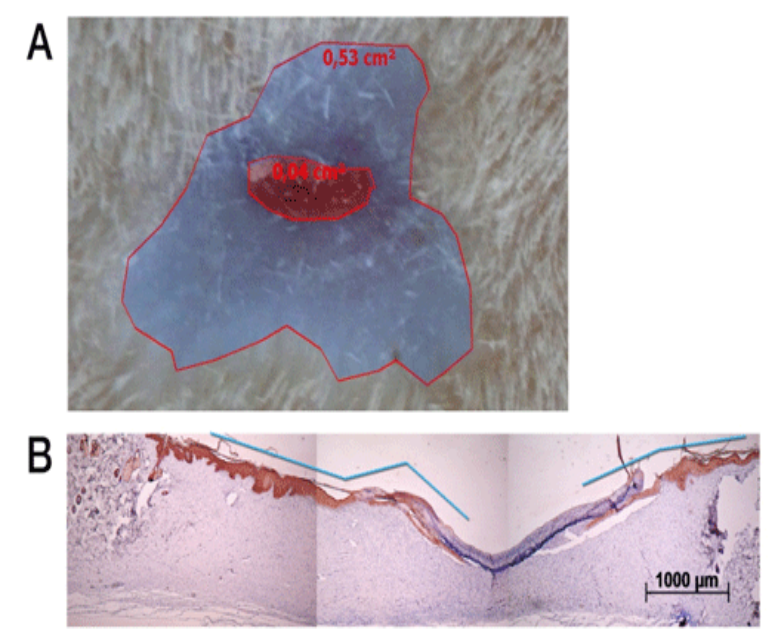

Figure 2: (A) Planimetric analysis to quantify the healed wound epidermis. The darker central area represents the non-epithelialized area with scab and lighter peripheral the epithelialized area. (B) Anti-cytokeratin $34 \beta \mathrm{E} 12$ immunostaining and epithelial progress measuring. The upper lines represent the length of the quantified epithelium.

\section{Histological immunofluorescence}

Immunofluorescence analysis was performed to identify grafted ASCs with GFP signal and identify the phenotype of ASCs grafted cells by adding antibodies against additional antigens. The primary antibody was anti-cytokeratin 19 (ab15463, 1:100, Abcam, Cambridge, MA). Before adding the primary antibody, $5 \mu \mathrm{m}$ frozen sections of fresh tissue samples were washed with PBS, then fixed with $3.7 \%$ paraformaldehyde for 10 minutes at room temperature, washed with PBS and $0.3 \%$ triton X-100 and submitted to blocking solution of PBS-BSA and $10 \%$ goat serum for 30 minutes at room temperature. The primary antibody was incubated for 1 hour at $37^{\circ} \mathrm{C}$, then washed with PBS, along with the secondary antibody, and incubated for another hour (antirabbit Texas red IgG, 1:200, Vector Laboratories, Inc., CA, USA). Then, the slides were washed with PBS, aqueous mounting medium was added (S3025 Faramount, Aqueous mounting medium, Dako) and a cover glass was placed. The slides were analyzed in a fluorescence microscope. 


\section{Statistical Analysis}

Statistical analysis was performed using Stata software version 10.0 for Windows (StataCorp, Texas, USA). The results are expressed as the mean \pm standard deviation. A t Student test was used for paired samples to determine the probability of statistical significance. A value of $p \leq 0.05$ was considered statistically significant.

\section{Results}

\section{Wound closure by planimetric analysis}

The wound closure was quantified by planimetry of surface analysis. When analyzing the wound size by contraction from the edges, no significant differences were found between the ASCs and the control side $(82.63 \% \pm 3.4 \%$ vs. $80.66 \% \pm 3.89 \%, p=$ $0.08)$; on the other hand, the epithelialized area was significantly greater in the ASCs than the control side $(93.47 \% \pm 5.98 \%$ vs. $79.88 \% \pm 6.28 \%, p=0.0028$ ) (Figure 3 ).

\section{Histology to quantify epithelial progression measured by immunohistochemistry anti-cytokeratin $34 \beta \mathrm{E} 12$}

All histological samples were positive for cytokeratin antibody 34ßE12. Linear microscopic quantization of the epithelium over the implant show that a significant difference exists in the ASCs side $(6440 \pm 485 \mu \mathrm{m}$ vs. $5402 \mu \mathrm{m} \pm 467, \mathrm{P}<0.001)$ (Figure 3 ).

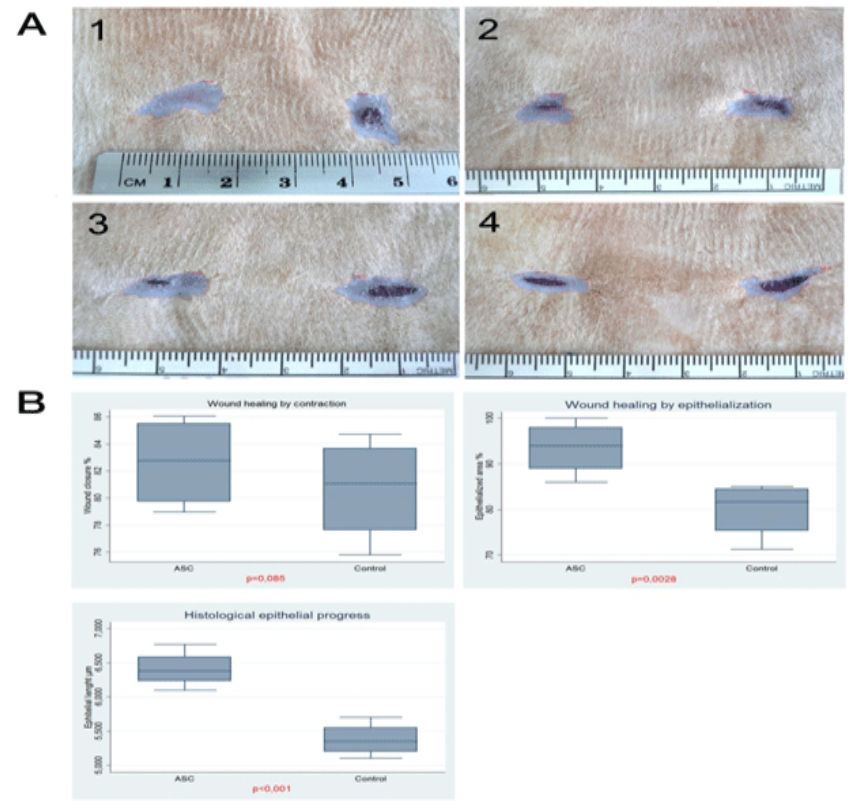

Figure 3: (A) Planimetric analysis results in the 4 animals. The left injury corresponds to ASC side. The marked area, enclosed by the line corresponds to the surface healed by contraction from the edges. (B) Left, wound healing determined by contraction from the edges, no statistically significant difference was found. Right, wound healing determined by epithelialization (epithelialized area), a statistically significant difference in favor to the ASCs side was found $(\mathrm{p}=0.0028)$. Left below, epithelial progress measured in histological sections stained by immunohistochemistry anti-cytokeratin 34ßE12 (epithelial length), a statistically significant difference in favor to ASCs side was found $(\mathrm{p}<0.001)$.

\section{Immunohistochemistry for tracking GFP labeled ASCs}

At the end of the study period, the GFP positive ASCs were identified inside the regenerated dermis. However, there was no migration of these cells in the epidermal epithelium, based on detection of GFP activity concomitant with the surface marker anti-cytokeratin 19 (Figure 4).

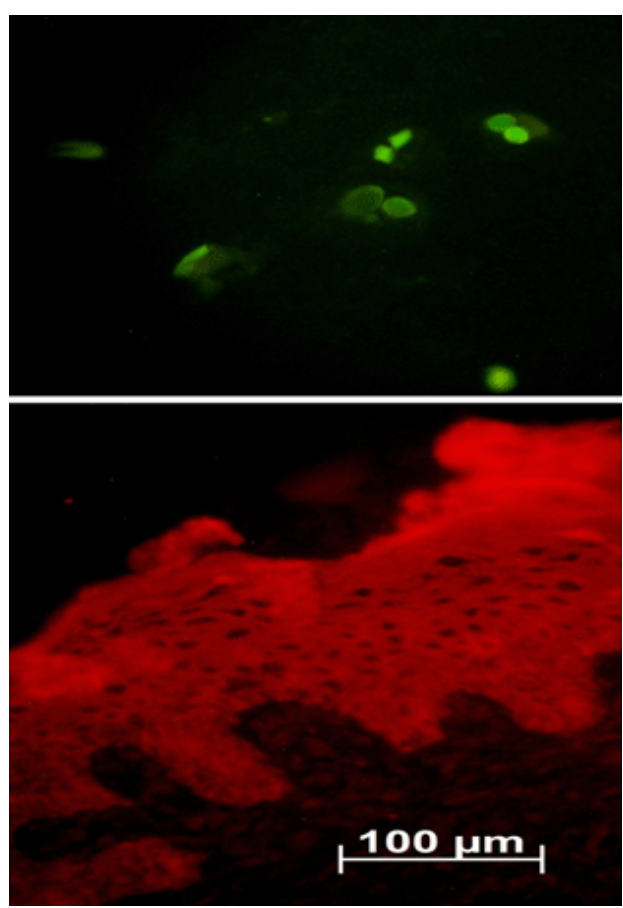

Figure 4: GFP positive cells located in the dermis of regenerated tissue (top). No GFP positive cells were located in the epidermal epithelium concomitant with the surface marker anti-cytokeratin 19 (bellow).

\section{Discussion}

During skin wound re-epithelialization, a wedge-shaped mass of keratinocytes moves across the granulation tissue. The keratinocytes that participate in these processes of migration and proliferation are derived from at least two anatomic locations, including those cells in close proximity to the wound and epidermal cells of nearby hair bulges. Keratinocytes are stimulated to migrate and proliferate by a number of factors during re-epithelialization. Among growth factors and cytokines, Epidermal Growth Factor (EGF) and Transforming Growth Factor (TGF)- $\beta$ play a role in keratinocyte migration $[21,22]$.

EGF and others ligands bind the EGF Receptor (EGFR) a tyrosine kinase transmembrane protein. EGFR plays an important role in reepithelialization by increasing keratinocyte proliferation and cell migration in acute wounds. EGF is potent mitogen for keratinocytes and the transmembrane forms are able to stimulate growth of keratinocytes in a juxtacrine manner. In wound healing, TGF- $\beta 1$ is important in inflammation, angiogenesis, reepithelialization, and connective tissue regeneration. During reepithelialization, TGF- $\beta 1$ shifts keratinocyte integrin expression toward a more migratory phenotype [23]. 
The results of this study showed how epithelial proliferation successfully increased on the dermal scaffold plus ASCs in an animal experimental model over 4 weeks of regeneration. We used a brief technique for seeding ASCs without prior expansion (SVF), and in 48 hours, our previous results were supported in terms of adhesion and cell viability on the dermal scaffold [17]. The only technical modification in this time was the use of circular instead of square dermal substitute because the circular shape is geometrically adapted to the bottom of the culture dish, allowing adherent cells to be included in greater proportion in the scaffold

Regarding the quantification of wound healing, the measurement of the epidermal epithelium over the graft is very important, not only the wound size. Because the wound size mainly depends of the myofibroblasts activity around the edges, as reflected in the present study, no significant differences in wound size were found [21]. Other experimental studies that used ASCs carried on dermal scaffolds or on collagen gels found important differences for the closure of the wounds treated with ASCs but using the wound size as a measurement parameter $[6,24,25]$.

In this study, the increased epithelialization cannot be explained by differentiation of ASCs in keratinocytes because at this time, no GFP activity was found in the epithelium. We are not in disagreement with the results presented by other studies that reflect, in a very illustrative way, how this differentiation exists at 4 weeks, but we must consider other alternatives to explain our results $[6,7,24,26]$. Rustad et al. recently postulated that MSCs (Mesenchymal Stem Cells) do not achieve transdifferentiation toward keratinocytes, but act by paracrine effects. The GFP marker was used in MSC, demonstrating the non-appearance of GFP+ MSCs in the healed wound epidermis [27]. They propose that structural microenvironments can significantly alter MSC behavior and can be used to manipulate their cytokine secretion profile. While the mechanism responsible for these upregulation cytokines and stemness factors is currently under investigation, a biostimulation between the delivery vehicle and ASCs that promotes epithelial formation is possible.

Yuan et al. exposed that the ASCs can promote the migration of Human Epidermal Keratinocytes (HEK) in vitro. The ASCs were directly co-cultured with HEK cells, and then confluent HEK cells were scraped to establish a wound model. After $72 \mathrm{hrs}$, the cell numbers that migrated across the edge of the wound was measured and the rate of wound healing was calculated. The number of cells were significantly higher and the wound healing was $61 \%$ significantly better than in a control group [28].

Moon et al. demonstrated the effects of Advanced AdiposeDerived Stem Cell Protein Extract (AAPE), obtained by the culture of ASCs in a hypoxic medium, on human keratinocytes in vitro, showing that AAPE in keratinocytes notably affected the expression of 290 identified transcripts, which were associated with cell proliferation, cycle and migration [29]. This treatment significantly stimulated stress fiber formation, which was linked to the RhoA-ROCK pathway, highlighting the importance of HGF, FGF-1, G-CSF, GM-CSF, IL-6, Vascular Endothelial Growth Factor (VEGF), and TGF- $\beta 3$, among other relevant proteins.
Furthermore, hair growth was documented by paracrine biostimulation of ASCs [30,31]. Park et al. identified the factors responsible for hypoxia-enhanced hair regeneration, finding increased proliferation of human follicle dermal papilla cells and epithelial keratinocytes, an increase in the insulin-like growth factor binding protein (IGFBP)-1, IGFBP-2, macrophage colonystimulating factor (M-CSF), M-CSF receptor, platelet-derived growth factor- $\beta$, and VEGF, as reported with angiogenic and fibroblastic induction $[25,30,32]$.

A last point to analyze is where to focus the benefits of faster healing. Logically, one goal is its use in situations, such as delayed healing, prolonged inflammation, low cellular infiltration, extracellular matrix reduction and reduction of growth factors, which occurs in diabetic foot [33]. However, in patients without healing problems, another goal should be to find a quicker method of skin regeneration, resulting in shorter hospital stays and fewer surgeries.

\section{Conclusions}

In this study, autologous Adipose-derived Stem Cells seeded on a commercially available dermal substitute significantly increased epithelial formation, most likely by a mechanism of induction rather than differentiation.

The simplicity of the performed method and the results provide support for clinical translation in the near future.

\section{References}

1. Vacanti JP, Langer R, Upton J, Marler JJ. Transplantation of cells in matrices for tissue regeneration. Adv Drug Deliv Rev. 1998;33(12):165-182.

2. Shevchenko RV, James SL, James SE. A review of tissue-engineered skin bioconstructs available for skin reconstruction. J R Soc Interface. 2010;7(43):229-258. doi: 10.1098/rsif.2009.0403

3. Burke JF, Yannas IV, Quinby WC, Jr., Bondoc CC, Jung WK. Successful use of a physiologically acceptable artificial skin in the treatment of extensive burn injury. Ann Surg. 1981;194(4):413-428.

4. Komorowska-Timek E, Gabriel A, Bennett DC, Miles D, Garberoglio C, Cheng C, et al. Artificial dermis as an alternative for coverage of complex scalp defects following excision of malignant tumors. Plast Reconstr Surg. 2005;115(4):1010-1017.

5. Jeng JC, Fidler PE, Sokolich JC, Jaskille AD, Khan S, White PM, et al. Seven years' experience with Integra as a reconstructive tool. J Burn Care Res. 2007;28(1):120-126.

6. Altman AM, Matthias N, Yan Y, Song YH, Bai X, Chiu ES, et al. Dermal matrix as a carrier for in vivo delivery of human adipose-derived stem cells. Biomaterials. 2008;29(10):1431-1442. doi: 10.1016/j. biomaterials.2007.11.026

7. Altman AM, Yan Y, Matthias N, Bai X, Rios C, Mathur AB, et al. IFATS collection: Human adipose-derived stem cells seeded on a silk fibroin-chitosan scaffold enhance wound repair in a murine soft tissue injury model. Stem Cells. 2009;27(1):250-258. doi: 10.1634/ stemcells.2008-0178

8. Liu S, Zhang H, Zhang $\mathrm{X}$, Lu W, Huang X, Xie H, et al. Synergistic angiogenesis promoting effects of extracellular matrix scaffolds and adipose-derived stem cells during wound repair. Tissue Eng Part A. 2011;17(5-6):725-739. doi: 10.1089/ten.TEA.2010.0331 
9. Orbay H, Takami Y, Hyakusoku H, Mizuno H. Acellular dermal matrix seeded with adipose-derived stem cells as a subcutaneous implant. Aesthetic Plast Surg. 2011;35(5):756-763. doi: 10.1007/s00266-0119683-2

10. Hassan WU, Greiser U, Wang W. Role of adipose-derived stem cells in wound healing. Wound Repair Regen. 2014;22(3):313-325. doi: 10.1111/wrr.12173

11. Gronthos S, Franklin DM, Leddy HA, Robey PG, Storms RW, Gimble JM. Surface protein characterization of human adipose tissue-derived stromal cells. J Cell Physiol. 2001;189(1):54-63.

12. Lee RH, Kim B, Choi I, Kim H, Choi HS, Suh K, et al. Characterization and expression analysis of mesenchymal stem cells from human bone marrow and adipose tissue. Cell Physiol Biochem. 2004;14(4-6):311324.

13. Katz AJ, Tholpady A, Tholpady SS, Shang H, Ogle RC. Cell surface and transcriptional characterization of human adipose-derived adherent stromal (hADAS) cells. Stem Cells. 2005;23(3):412-423.

14. Liu TM, Martina M, Hutmacher DW, Hui JH, Lee EH, Lim B. Identification of common pathways mediating differentiation of bone marrow- and adipose tissue-derived human mesenchymal stem cells into three mesenchymal lineages. Stem Cells. 2007;25(3):750-760

15. Meruane M, Rojas M. Células Troncales Derivadas del Tejido Adiposo. Int J Morphol. 2010;28(3):879-889.

16. da Silva Meirelles L, Chagastelles PC, Nardi NB. Mesenchymal stem cells reside in virtually all post-natal organs and tissues. J Cell Sci. 2006;119(Pt 11):2204-2213

17. Meruane MA, Rojas M, Marcelain K. The use of adipose tissue-derived stem cells within a dermal substitute improves skin regeneration by increasing neoangiogenesis and collagen synthesis. Plast Reconstr Surg. 2012;130(1):53-63. doi: 10.1097/PRS.0b013e3182547e04

18. Lindroos B, Suuronen R, Miettinen S. The potential of adipose stem cells in regenerative medicine. Stem Cell Rev. 2011;7(2):269-291. doi: 10.1007/s12015-010-9193-7

19. Yoshimura K, Shigeura T, Matsumoto D, Sato T, Takaki Y, Aiba-Kojima $\mathrm{E}$, et al. Characterization of freshly isolated and cultured cells derived from the fatty and fluid portions of liposuction aspirates. J Cell Physiol. 2006;208(1):64-76.

20. Eto $H$, Suga $H$, Matsumoto $D$, Inoue $K$, Aoi $N$, Kato $H$, et al. Characterization of structure and cellular components of aspirated and excised adipose tissue. Plast Reconstr Surg. 2009;124(4):10871097. doi: 10.1097/PRS.0b013e3181b5a3f1

21. Singer AJ, Clark RA. Cutaneous wound healing. N Engl J Med 1999;341(10):738-746.
22.Baum CL, Arpey CJ. Normal cutaneous wound healing: clinical correlation with cellular and molecular events. Dermatol Surg 2005;31(6):674-686; discussion 86.

23. Barrientos S, Stojadinovic O, Golinko MS, Brem H, Tomic-Canic M. Growth factors and cytokines in wound healing. Wound Repair Regen 2008;16(5):585-601. doi: 10.1111/j.1524-475X.2008.00410.x

24. Nie C, Yang D, Xu J, Si Z, Jin X, Zhang J. Locally administered adiposederived stem cells accelerate wound healing through differentiation and vasculogenesis. Cell Transplant. 2011;20(2):205-216. doi: 10.3727/096368910X520065

25.Kim WS, Park BS, Sung JH, Yang JM, Park SB, Kwak SJ, et al. Wound healing effect of adipose-derived stem cells: a critical role of secretory factors on human dermal fibroblasts. J Dermatol Sci. 2007;48(1):1524

26. Ebrahimian TG, Pouzoulet F, Squiban C, Buard V, Andre M, Cousin B, et al. Cell therapy based on adipose tissue-derived stromal cells promotes physiological and pathological wound healing. Arterioscler Thromb Vasc Biol. 2009;29(4):503-510. doi: 10.1161/ATVBAHA.108.178962

27. Rustad KC, Wong VW, Sorkin M, Glotzbach JP, Major MR, Rajadas J, et al. Enhancement of mesenchymal stem cell angiogenic capacity and stemness by a biomimetic hydrogel scaffold. Biomaterials. 2012;33(1):80-90.

28.Yuan F, Lei YH, Fu XB, Sheng ZY, Cai S, Sun TZ. [Promotive effect of adipose-derived stem cells on the wound model of human epidermal keratinocytes in vitro]. Zhonghua Wai Ke Za Zhi. 2008;46(20):15751578.

29. Moon KM, Park YH, Lee JS, Chae YB, Kim MM, Kim DS, et al. The effect of secretory factors of adipose-derived stem cells on human keratinocytes. Int J Mol Sci. 2012;13(1):1239-1257. doi: 10.3390/ ijms13011239

30. Park BS, Kim WS, Choi JS, Kim HK, Won JH, Ohkubo F, et al. Hair growth stimulated by conditioned medium of adipose-derived stem cells is enhanced by hypoxia: evidence of increased growth factor secretion. Biomed Res. 2010;31(1):27-34.

31. Festa E, Fretz J, Berry R, Schmidt B, Rodeheffer M, Horowitz M, et al. Adipocyte lineage cells contribute to the skin stem cell niche to drive hair cycling. Cell. 2011;146(5):761-771.

32. Rehman J, Traktuev D, Li J, Merfeld-Clauss S, Temm-Grove CJ, Bovenkerk JE, et al. Secretion of angiogenic and antiapoptotic factors by human adipose stromal cells. Circulation. 2004;109(10):1292-1298.

33. Falanga V. Wound healing and its impairment in the diabetic foot Lancet. 2005;366(9498):1736-1743. 